\title{
Correction to: Copeptin, miRNA-208, and miRNA-499 as New Biomarkers for Early Detection of Acute Coronary Syndrome
}

\author{
Marwa A. Gaber ${ }^{1}$. Omnia H. M. Omar ${ }^{2}$ Sahar E. M. El-Deek ${ }^{1}$ Ayman K. M. Hassan ${ }^{3}$. \\ Marwan S. Mahmoud ${ }^{3} \cdot$ Abdel-Raheim M. A. Meki $^{1,4}$
}

Published online: 9 November 2021

๑) Springer Science+Business Media, LLC, part of Springer Nature 2021

\section{Correction to: Applied Biochemistry and Biotechnology https://doi.org/10.1007/s12010-021-03695-6}

The original version of this article unfortunately contained mistakes in the authors' affiliations and the type of the article. The correct affiliations are shown here. The article type is Original Article.

The original article has been corrected.

Publisher's Note Springer Nature remains neutral with regard to jurisdictional claims in published maps and institutional affiliations.

The original article can be found online at https://doi.org/10.1007/s12010-021-03695-6.

Marwa A. Gaber

marwagaber@aun.edu.eg; marwagaberbio@yahoo.com

1 Medical Biochemistry Department, Faculty of Medicine, Assiut University, Assiut, Egypt

2 Assiut International Center of Nanomedicine, El-Rajhy Liver Hospital, Assiut University, Assiut, Egypt

3 Cardiology Department, Faculty of Medicine, Assiut University, Assiut, Egypt

4 Biochemistry Department, Faculty of Pharmacy, Sphinx University, New Assiut, Egypt 